\title{
Blow-up of result in a nonlinear wave equation with delay and source term
}

\author{
Tayeb Lakroumbe ${ }^{1}$, Mama Abdelli ${ }^{2}$, and Abderrahmane Beniani ${ }^{3}$ \\ ${ }^{1}$ University of Djillali Liabes Faculty of Exact Sciences \\ ${ }^{2}$ University of Djillali Liabes Sidi Bel Abbes \\ ${ }^{3}$ Center University of Belhadj Bouchaib -B.P. 284 RP, Ain Temouchent
}

June 28,2020

\begin{abstract}
In this paper we consider the initial boundary value problem for a nonlinear damping and a delay term of the form:

$$
\left|u_{t}\right|^{l} u_{t t}-\Delta u(x, t)-\Delta u_{t t}+\mu_{1}\left|u_{t}\right|^{m-2} u_{t}+\mu_{2}\left|u_{t}(t-\tau)\right|^{m-2} u_{t}(t-\tau)=b|u|^{p-2} u
$$

with initial conditions and Dirichlet boundary conditions. Under appropriate conditions on $\mu_{1}, \mu_{2}$, we prove that there are solutions with negative initial energy that blow-up finite time if $p \geq \max \{l+2, m\}$.

\section{Hosted file}

Beniani-Abdelli-Blow-up.pdf available at https://authorea.com/users/337362/articles/462957blow-up-of-result-in-a-nonlinear-wave-equation-with-delay-and-source-term
\end{abstract}

